\title{
The Carboxyl Terminal Sequence of Rat Transporter Associated with Antigen Processing (TAP)-Like (ABCB9) is Heterogeneous due to Splicing of Its mRNA
}

\author{
Yoko Yamaguchi, Hiroko Iseoka, Ayako Kobayashi, and Masatomo MaedA* \\ Laboratory of Biochemistry and Molecular Biology, Graduate School of Pharmaceutical Sciences, Osaka University; \\ Suita, Osaka 565-0871, Japan. Received August 18, 2003; accepted September 16, 2003
}

\begin{abstract}
Transporter associated with antigen processing (TAP)-like (TAPL) is a half-type ATP-binding cassette (ABC) transporter with sequence similarity to TAP1 and TAP2 and is highly conserved in mammals. Tissue distribution of the TAP family (TAP1, TAP2, TAPL) in rat was investigated using the semi quantitative reversetranscriptase polymerase chain reaction (RT-PCR). In young male rat, greater amounts of TAPL mRNA were detected in the brain and testis than in the thymus and intestine. On the other hand, both TAP1 and TAP2 mRNAs had higher expression in the thymus. Furthermore, the expression level of TAP1 in the intestine and that of TAP2 in the brain and testis were also high. Analysis of rat TAPL cDNAs demonstrated that the carboxyl terminal sequence of the ATP-binding region was heterogeneous. At least four different isoforms (C-I, -II, -III, -IV) could be produced by alternative splicing of mRNA, as was confirmed by a genomic data search. Both C-III and C-IV types had shorter carboxyl-terminal sequences, and the C-III had the shortest sequence. The functional heterogeneity of the carboxyl-terminal splicing variants of TAPL is discussed.
\end{abstract}

Key words ATP-binding cassette B9; splicing; expression; transporter associated with antigen processing-like; ATP-binding cassette $(\mathrm{ABC})$ transporter

The ATP-binding cassette $(\mathrm{ABC})$ transporters with a conserved ATP-binding domain, called ABC, are widely distributed in the membranes of various organisms from prokaryotes to eukaryotes. ${ }^{1)}$ The results of the genome project suggest that there are as many as 50 different genes for this family in human, fly and nematode (http://www.humanabc.org). Eukaryotic $\mathrm{ABC}$ transporters have two general domains; one is a cluster of transmembrane segments and another is cytoplasmic with an $\mathrm{ABC}$ sequence. While two pairs of these domains are arranged alternatively in a single molecule of a complete-type transporter, a half-type transporter with each transmembrane and cytoplasmic domains forms a homo- or hetero dimer to be functional. ${ }^{2)}$ They transport wide varieties of substrates from inorganic and organic ions to various xenobiotics and biomolecules. ${ }^{3)}$ Furthermore, it is well known that mutations of the transporter genes causes congenital diseases such as cystic fibrosis, adrenoleukodystrophy, and bare lymphocyte syndrome. ${ }^{4)}$

Recently, we found a novel half-type $\mathrm{ABC}$ transporter gene expressed in mammals. ${ }^{5,6)}$ This putative transporter has a high degree of amino acid sequence similarity to transporter associated with antigen processing (TAP) 1 and TAP2, and thus is called TAP-like (TAPL, ABCB9). These three members are classified into subgroup $B$ with multidrug resistance (MDR) among various ABC transporters. ${ }^{6,7)}$ The TAP heterodimer, TAP1 and TAP2, transports antigen peptides into the lumen of the endoplasmic reticulum from the cytoplasm coupled to ATP hydrolysis. ${ }^{8)}$ The transported peptides are presented as cell surface antigens by major histocompatibility complex (MHC) class I molecules. The conservation of the peptide-binding motifs of TAP proteins in TAPL suggests that TAPL might be a peptide transporter. ${ }^{6,7)}$

In this study, we found that the carboxyl-terminal sequence of rat TAPL is heterogeneous due to the splicing of its mRNA. We discuss the significance of the carboxyl-terminal diversity of TAPL from the viewpoint of functional heterogeneity.

\section{MATERIALS AND METHODS}

cDNA Cloning by $3^{\prime}$-Rapid Amplification of cDNA Ends Total RNA was extracted from tissues of 5-week-old Sprague-Dawley male rats using the guanidine thiocyanateCsCl method.9) The first stranded cDNA was synthesized from $5 \mu \mathrm{g}$ of RNA with the SuperScript Preamplification System (Gibco BRL) with oligo $\mathrm{dT}_{15}$ Primer. 3'-Downstream sequences were amplified using $3^{\prime}$-rapid amplification of cDNA ends (RACE) (3'-RACE System, Gibco BRL) using rat cDNA from brain and testis and primers YY005 and YY006. cDNA was also obtained by polymerase chain reaction (PCR) with primer pairs YY011 and YY020, and then YY011 and YY021 (Table 1A). The PCR conditions ${ }^{10)}$ for these experiments were 35 cycles of denaturation $\left(94^{\circ} \mathrm{C}\right.$, $1 \mathrm{~min}$ ), annealing $\left(55^{\circ} \mathrm{C}, 2 \mathrm{~min}\right)$, and extension $\left(72^{\circ} \mathrm{C}\right.$, $3 \mathrm{~min})$. In all PCR, preheating $\left(94^{\circ} \mathrm{C}, 3 \mathrm{~min}\right)$ and postincubation $\left(72{ }^{\circ} \mathrm{C}, 7 \mathrm{~min}\right)$ were carried out before and after successive cycle reactions, respectively.

DNA Sequencing Amplified cDNAs were analyzed by agarose gel electrophoresis [1\%, (w/v) Takara Type LO3] using TAE buffer (X 1). ${ }^{9}$ The DNA fragment (about $0.3 \mathrm{kbp}$ ) was ligated to the pCRII vector (Invitrogen) or pGEM T-Easy vector (Promega). Both strands of cloned DNA were sequenced by means of the dideoxy chain-termination method $^{11)}$ using a Shimadzu DNA Sequencer Model DSQ1000L with a Thermo Sequenase fluorescent-labeled primer cycle sequencing kit (Amersham Pharmacia Biotech) or using an ABI PRISM ${ }^{\mathrm{TM}} 310$ Genetic Analyzer with a Big Dye $^{\mathrm{TM}}$ Terminator Cycle sequencing Ready Reaction Kit (Applied Biosystems) and sequence primers (M13 forward and reverse).

Reverse-Transcriptase PCR (RT-PCR) cDNA was synthesized as described in the section for cDNA cloning. One microliter of reaction product was subjected to semiquantitative PCR analysis using the primer pairs shown in Table 1 (A, B). Under the conditions of 35 cycles, the denat- 
Table 1. Primer Sequences and Their Combinations for PCR

(A)

$\begin{array}{ll}\text { YY003 } & \text { 5'-GGTCATAGGCGCCGATGGGC-3' } \\ \text { YY005 } & \text { 5'-AGCCCAGCTGTCAGGTGGCC-3' } \\ \text { YY006 } & \text { 5'-TGGCACGTGCACTAGTGCGG-3' } \\ \text { YY009 } & \text { 5'-TTGTCCTGGGAGACTGCATGGA-3' } \\ \text { YY011 } & 5^{\prime} \text {-CTCCACCAATCTGAGAATAC-3' } \\ \text { YY020 } & 5^{\prime} \text {-GGCCTTGCCCCGGTGAG-3' } \\ \text { YY021 } & 5^{\prime} \text {-AAGCCTGCCCCTGTCACC-3' } \\ \text { YY067 } & 5^{\prime} \text {-ACTGCTCCGGGTCTGGG-3' } \\ \text { YY068 } & 5^{\prime} \text {-AACTTGTGCCACAGGGC-3' } \\ \text { YY069 } & 5^{\prime} \text {-CCGGGGCTGCCAGGACT-3' } \\ \text { MK042 } & 5^{\prime} \text {-GGCATGGGGTCAAAATCACC-3' } \\ \text { rat } \beta-S & 5^{\prime} \text {-CAAGAGATGGCCACTGCCGCA-3' } \\ \text { rat } \beta-A & 5^{\prime} \text {-TCCTTCTGCACTCTGTCAGCG-3' }\end{array}$

(B)

\begin{tabular}{lll}
\hline \hline Gene & \multicolumn{2}{c}{ Primers } \\
\hline TAPL & YY003 & YY009 \\
TAP1 & YY067 & YY068 \\
TAP2 & YY069 & MK042 \\
$\beta$-Actin & Rat $\beta$-S & Rat $\beta$-A \\
\hline
\end{tabular}

Sequences of primers (A) and their combinations (B) for PCR amplification of rat TAPL, TAP1, and TAP2 cDNAs are indicated. The primers for $\beta$-actin were used to normalize the PCR amplification.

uration, annealing, and extension conditions $\left(94^{\circ} \mathrm{C}, 0.5 \mathrm{~min}\right.$, $59^{\circ} \mathrm{C}, 0.5 \mathrm{~min}, 72^{\circ} \mathrm{C}, 0.5 \mathrm{~min}$, respectively) were common for the amplification of rat TAPL, TAP1, and TAP2 cDNAs. Either dimethyl sulfoxide $(5 \%, \mathrm{v} / \mathrm{v})$ or betaine $(1.25 \mathrm{M})$ was added to the reaction mixture. The rat $\beta$-actin mRNA level was determined using PCR with primers rat $\beta$-S and rat $\beta$ $\mathrm{A}^{5)}$ under the conditions of 25 cycles of denaturation $\left(94^{\circ} \mathrm{C}\right.$, $1 \mathrm{~min})$, annealing $\left(60^{\circ} \mathrm{C}, 0.5 \mathrm{~min}\right)$, and extension $\left(72^{\circ} \mathrm{C}\right.$, $1 \mathrm{~min})$. Preheating and postincubation were carried out as for cDNA cloning. After agarose gel electrophoresis $(1.8 \%$, $\mathrm{W} / \mathrm{v}),{ }^{9)}$ the DNA bands were visualized with ethidium bromide and their images were processed on a FluoroImager Model 595 (Molecular Dynamics).

Chemicals Restriction enzymes were obtained from New England Biolab, TaKaRa Shuzo, Toyobo, and Nippon Gene. T4 DNA ligase was from TaKaRa or Toyobo, and Taq polymerase from Nippon Gene or Perkin Elmer. The PCR primers were purchased from Gibco BRL. All other chemicals used were of the highest grade commercially available.

\section{RESULTS AND DISCUSSION}

Tissue-Specific Expression of Rat TAPL Different from Those of TAP1 and TAP2 Although TAPL is transcribed ubiquitously, its expression level is different in various rat tissues. ${ }^{5)}$ Human and mouse TAPL showed also tissue-specific expression in the brain and testis. ${ }^{7}$ ) We first confirmed this expression pattern of TAPL using semi quantitative RT-PCR. We analyzed total transcription levels of TAPL in four tissues (brain, thymus, intestine, and testis) from young male rats (6 weeks of age) and compared them with those of the other TAP family members, TAP1 and TAP2. The results demonstrated that the expression of TAPL is higher in the brain and testis than in the thymus and intestine (Fig. 1). This was in contrast to TAP1 and TAP2, since they were expressed at a

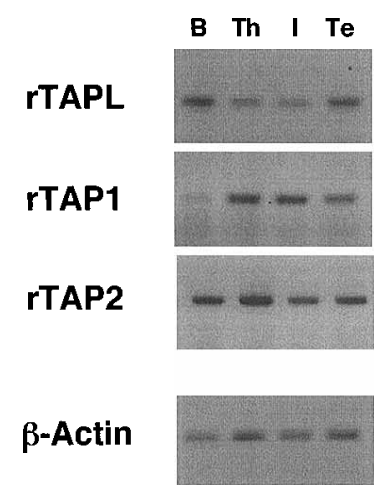

Fig. 1. mRNA Levels of TAPL, TAP1 and TAP2 in Rat Tissues

Expression of TAPL, TAP1, and TAP2 mRNA in young male rats was determined using RT-PCR. Total RNA was prepared from rat tissues (B; brain, Th; thymus, I; intestine Te; testis) and subjected to RT-PCR. The products $(366,290,468$ bp for rat TAPL, TAP1, TAP2, respectively) were analyzed with agarose gel electrophoresis and staining with ethidium bromide. The mRNA level of $\beta$-actin (278 bp) was also determined as a control.

higher level in the thymus. Furthermore, the expression levels of TAP 1 in the intestine and of TAP 2 in the brain and testis were also high. These results are interesting from the viewpoint of the roles of TAP1 and TAP2 in tissues other than immune systems.

Heterogeneity of the Carboxyl-Terminal Sequence of Rat TAPL We previously reported that two types of clone were obtained by $3^{\prime}$-RACE of rat kidney cDNA, C-I and CII. Both the C-I and C-II types were suggested to be splicing isoforms with some 40 different carboxyl-terminal residues. ${ }^{5)}$ We also identified an additional type, C-III, in rat testis cDNA, when the entire cDNA sequence was amplified by PCR (Fig. 2A). The C-III clone had a 57-bp insertion immediately downstream from the nucleotide sequence corresponding to the Walker B motif. ${ }^{12)}$ Furthermore, the C-IV type sequence was reproducibly obtained by 3 '-RACE of rat brain cDNA (Fig. 2A).

The nucleotide sequences and the deduced amino acid sequences of these four carboxyl-terminal isoforms are shown in Figs. 2A and B. The amino acid residue numbers of these four isoforms (from C-I to C-IV) from the Walker B motif were $86,90,17$, and 32, respectively. Both the C-III and CIV types had shorter carboxyl-terminal sequences, and the $\mathrm{C}$ III had the shortest.

Gene Organization of the Rat TAPL Isoforms The comparison of cDNA sequences suggested that the C-I to CIV isoforms could have originated from splicing of mRNA. To determine the gene organization of rat TAPL isoforms, we compared the cloned sequences with the rat WGS supercontig on chromosome 12 (definition no. NW_042790) in a BLAST search. The relative locations of the carboxyl-terminal sequences of TAPL isoforms in the rat genome are presented in Fig. 3A. The sequences corresponding to the carboxyl-terminal variants of rat TAPL were found to be located 3' downstream from exon 11 in the Rat Genome Database (Fig. 3B). In the case of C-III, an additional novel exon, termed exon III, was inserted between the 11 th and 12 th exons of rat TAPL C-I/II. On the other hand, C-IV utilized another exon, termed exon IV, which was located between the 11th exon and exon III. Thus we concluded that two novel isoforms could be produced by alternative splicing of 
(A)

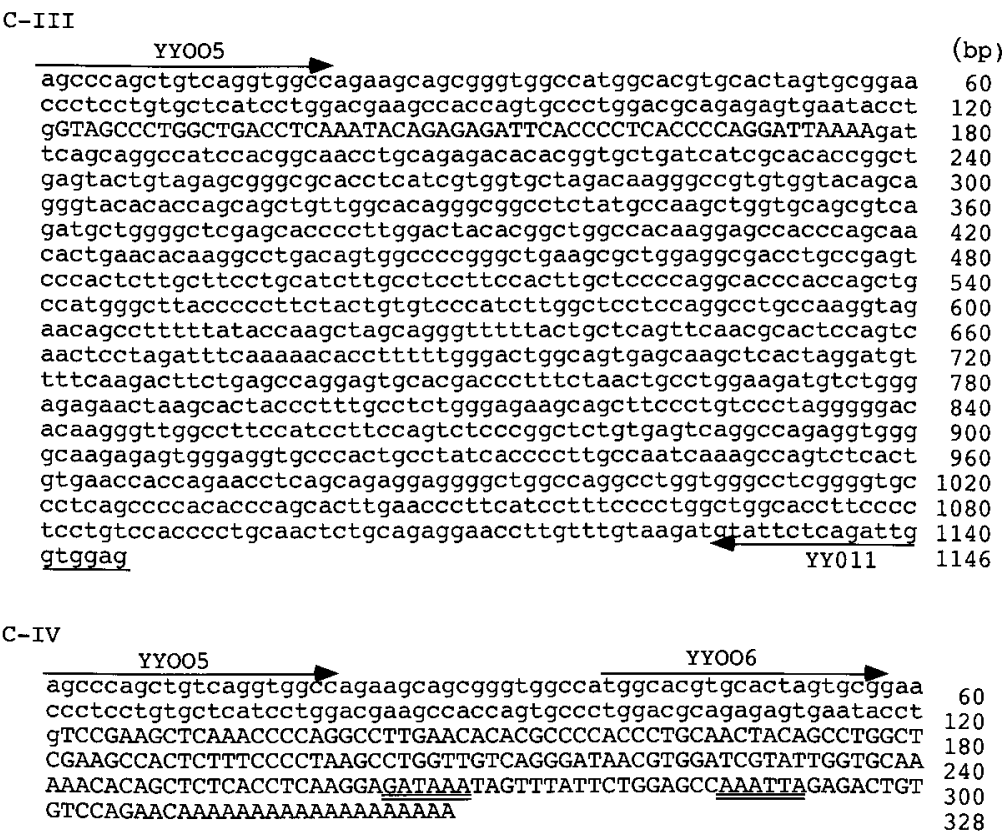

(B)

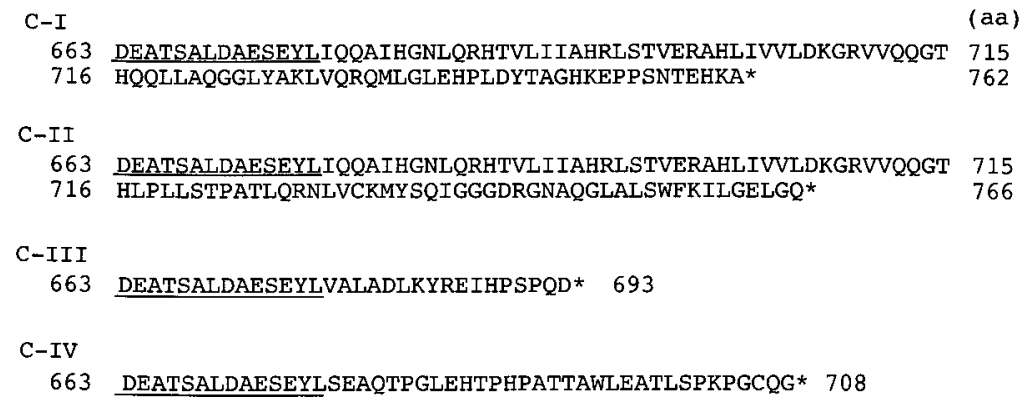

Fig. 2. Primary Sequences of Rat TAPL Isoforms

(A) Carboxyl-terminal sequences for rat TAPL isoforms (C-III, C-IV) are shown. The C-III sequence was amplified by PCR with primers YY005 and YY011 indicated in the figure. The C-IV sequence was amplified by $3^{\prime}$-RACE with primers YY005 and YY006. C-III could be generated by the insertion of the 57-bp additional exon (shown by capital letters) to the mRNA for C-I. ${ }^{5}$ Since the C-IV clone had a poly-A sequence, the AT-rich sequences (double underlined) could function as a poly-A additional signal. ${ }^{17)}$ The nucleotide sequences for rat TAPL carboxyl-terminal regions C-III and C-IV have been submitted to DDBJ/EMBL/GenBank under accession numbers AB116264 and AB116265, respectively. (B) Amino acid sequences were deduced from the cloned cDNAs. They were aligned from the Walker B sequence (DEATSALD). ${ }^{12}$ The sequence encoded by the 11 th exon is indicated by the underline.

the 12th exon.

Significance of the Presence of TAPL Isoforms Heterogeneity of the carboxyl-terminal region of rat TAPL could be important for the functions and regulations of TAPL, especially in terms of the cellular homeostasis. Plasma membrane $\mathrm{Ca}^{2+}$-ATPase may be one good example: the splicing events of PMCA1 mRNA produce isoforms with an altered calmodulin-binding domain and without a phosphorylation site by protein kinase A. ${ }^{13)}$ Closely related TAP2 has a splicing isoform, TAP2iso, with different substrate recognition. ${ }^{14)}$ Furthermore, a related $\mathrm{ABC}$ transporter member, SUR2, has splicing isoforms with altered ATP binding. ${ }^{15,16)}$ The carboxyl-terminal heterogeneity of TAPL could also contribute to changes in substrate recognition, dimer formation, and interaction with other proteins, which would affect cross-talk with cellular metabolic and signal transduction pathways.

Although it is reported that the TAP family (TAPL, TAP1,
TAP2) is widely expressed in various tissues, ${ }^{5,8)}$ the present results clearly indicate that the expression levels are different among the members and in different tissues. Thus the assembly and localization of TAP family proteins as well as their isoforms would be interesting, and these lines of study are now in progress.

Acknowledgments This research was supported in part by grants from the Ministry of Education, Culture, Sports, Science and Technology [Grant-in-Aid for Scientific Research C (13672284)], Japan Society for the Promotion of Science [Grants-in-Aid for Scientific Research on Priority Areas A (13033027) and B (13142206)], and from the Japan Foundation for Applied Enzymology (to M. M.) and the Mochida Memorial Foundation for Medical and Pharmaceutical Research (to A. K.). 
(A)

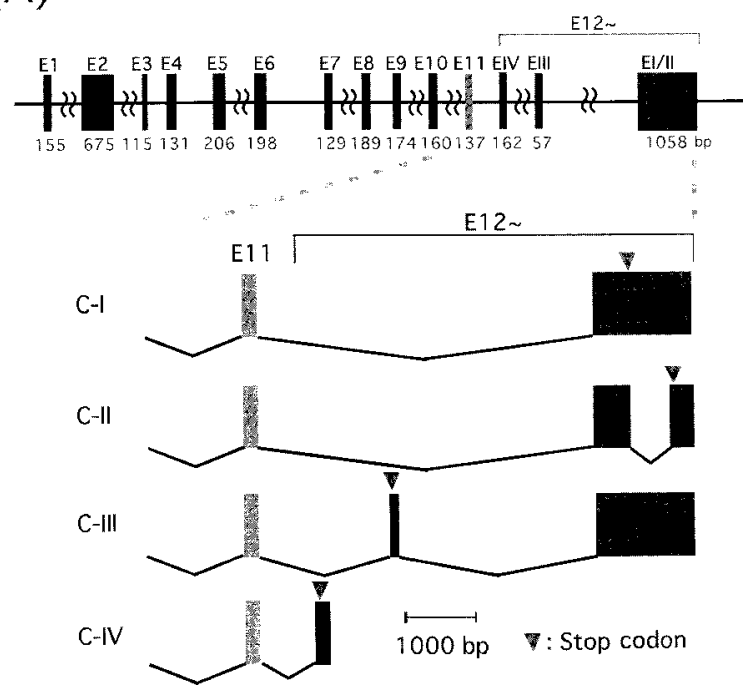

Fig. 3. Genomic Structure of Rat TAPL

(A) Exon and intron organizations of rat TAPL isoforms are shown. The cytogenetic localizations of the TAPL gene as well as the 12th exons were analyzed by means of a BLAST search of the Rat Genome Project WGS supercontig sequence on the 12th chromosome. Different 12th exons in the TAPL isoforms are denoted as I/II, III, and IV, respectively. In the gene diagram, exons are represented by vertical bars and introns by horizontal lines. The upper and lower numerical values indicate the exon number and size (bp), respectively. The positions of termination codons are indicated by arrowheads in the expanded portions. Exon EIII was connected to exon EI/II by further splicing. Since exon EIV was assigned from the cDNA sequence (Fig. 2A), there is a possibility that the EIV sequence would further extend downstream. (B) Genomic sequence from intron 11 to exon EI/II. Exons are indicated by bold letters with exon numbers. The end of exon EI/II is shown by our cloned cDNA.) The underlined part in EI/II is deleted in a C-II type clone.

(B)

tgaatggaga ggcetcctaa taactcaccc tgtgtetcet ccccacagag accggggaaa agggagccea getgtcaggt ggccagaage agcgggtgge catggcacgt gcactagtge ggaaccetce tgtgctcatc ctggacgaag ccaccagtge cetggacgca gagagtgaat acctggtaag tgggggcagc agatgctatg gcaggcggcc aggccgaggg tggccacagg ttctctcagg ccatgagcag gaaacggagt tctgggcacg gatacccagc tccatgcaga gctacagccc agtgacatgg gtaaaccggg ccagccagag gatctgatga ggagcccegc cetgcggtgt actcctgagt ttcttccctc ctcctccetc tgcggtctac cttccttgo tottgttett cagrCCGAAG CTCAAACCCC AGGCCTIGAA CACACGCCCC ACCCTGCAAC TACAGCCTGG CTCGAAGCCA CTCTTTCCCC TAAGCCTGGT TGTCAGGGAT AACGTGGATC GTATTGGTGC AAAAACACAG CTCTCACCTC AaGgAGATAA ATAGTTtatT CTGGaGcCAA ATTAGAGACT GTGTCCAGAA Cagactcggg tcatctcgat ttcatgatca acctggaaac agtctccagt gtcatgaagt tttcctagta acagaacgat agtgtcatga attaagaccc tcttcaaata catggatggg gtgtcgggge ggttacaggg gagctgggga gctgtcacag gcttcatttg cagtctgtta acactctcag cttttgggtt ggtctgctaa ctcgaccett tccaaagga ctttgttagt cacagcttgc tgaggctgac acagagtggg caaggacgac cctagatggt tgaaattcet gaggtattac catatctcta atgagacaca cactgctttc cagaattct cagccacagt tccttgtggg ctaagtatga $\langle 1 \mathrm{kbp}>$

EIII

attgttcta thgactiat tggctggact ttgtttctga gacagGTAGC CCTGGCTGAC CTCAAATACA GAGAGATTCA CCCCTCACCC CAGGATTAAA AGgtgtgcac caccacgccc agctatatat atatttttt toggagctga ggaccaaacc cagggccttg tgctttctag gcaagcgctc taccactgag ctaaatcccc aacccctatg tattttttt ttcttaataa gaaggtgttg actgtaagaa tcttgattta aaatatcgat atccttggaa tggagggttt tttaaagga gatttaaat aagttgtca atttaaacc aatttttag atttatttat tatgtataca gcatactgcc tgtaggccag aagacagcac $<6 \mathrm{kbp}>$

tgttcatttt acaaccagg aacggaatgt cagatagcag ccagcagggg gtaggtgaag gtgtgtatgt gctgggtggg gtgatttgca ggaggtggtg cagtgcagco tetgagcetg ctcaccttg ttccetcctc ctacagattc agcaggccat ccacggcaac ctgcagagac acacggtgct gatcatcgca caccggctga gtactgtaga gcgggcgcac ctcatcgtgg tgctagacaa gggccgtgtg gtacagcagg gtacacacca gcagctgttg gcacagggca gcctctatgc caagctggtg cagcgtcaga tgctggggct cgagcaccce ttggactaca cggctggcca caaggagcca cccagcaaca ctgaacacaa ggcetgacag tggccccggg ctgaagcgct ggaggcgace tgccgagtcc cactcttgct tcctgcatct tgcctccttc cacttgctcc ccaggcacce accagetgce atgggcttac cccettctac tgtgtcccat cttggctcet ccaggcctge caaggtagaa cagccttttt aaaccaagct agcagggttt ttactgctca gttcaacgca ctccagtcaa ctcctagatt tcaaaaacac ctttttggga ccggcagtga gcaagctcac taggatgttt tcaagacttc tgagccagga gtgcacgace ctttctaact gcctggaaga tgtctgggac agaactaagc actaccettt gcctctggga gaagcagctt ccetgtccce tagggggaca caagggttgg cettccatce ttccagtctc ccggetctgt gagtcaggce agaggtgggg caagagagtg ggaggtgcec actgcctatc accecttgce aatcaaagce agtctcactg tgaaccacca gaacctcagc agaggagggg ctggccaggc ctggtgggce teggggtgec ctcagcccca cacccagcac ttgaaccett catcctttce cetggetgge accttcecet cetgtccacc cetgcaactc tgcagaggaa ccttgtttgt aagatgtatt ctcagattgg tggaggggac cgaggcaatg cccagggtct ggctttgtcc tggtttaaga ttttgggaga actgggtcaa taaagtgtac tacctctgac ctctaccccg tctgtttec ttggatctgg ctctctgggc cttgacagta gacagcggca gagagtttgg tgctgtgtct tggagtccet gtctgtgttg 


\section{REFERENCES}

1) Hyde S. C., Emsley P., Hartshorn M. J., Mimmack M. M., Gileadi U., Pearce S. R., Gallagher M. P., Gill D. R., Hubbard R. E., Higgins C. F., Nature (London), 346, 362-365 (1990).

2) Croop J. M., "Methods in Enzymology," Vol. 292, ed. by Ambudkar S. V., Gottesman M. M., Academic Press, New York, 1998, pp. 101-116.

3) Klein I., Sarkadi B., Varadi A., Biochim. Biophys. Acta, 1461, $237-$ 262 (1999).

4) Decottignies A., Goffeau A., Nat. Genet., 15, 137-145 (1997).

5) Yamaguchi Y., Kasano M., Terada T., Sato R., Maeda M. FEBS Lett., 457, 231-236 (1999).

6) Kobayashi A., Kasano M., Maeda T., Hori S., Motojima K., Suzuki M., Fujiwara T., Takahashi E., Yabe T., Tanaka K., Kasahara M., Yamaguchi Y., Maeda M., J. Biochem. (Tokyo), 128, $711-718$ (2000).

7) Zhang F., Zhang W., Liu L., Fisher C. L., Hui D., Childs S., DoroviniZis K., Ling V., J. Biol. Chem., 275, 23287-23294 (2000).

8) Heemels M.-T., Ploegh H., Annu. Rev. Biochem., 64, $463-491$ (1995).
9) Sambrook J., Fritsch E. F., Maniatis T., "Molecular Cloning. A Laboratory Manual," 2nd ed., Cold Spring Harbor Laboratory Press, New York, 1989.

10) Saiki R. K., Gelfand D. H., Stoffel S., Scharf S. J., Higuchi R., Horn G. T., Mullis K. B., Erlich H. A., Science, 239, 487-491 (1988).

11) Sanger F., Coulson A. R., Barrell B. G., Smith A. J. H., Roe B. A., J. Mol. Biol., 143, 161-178 (1980).

12) Walker J. E., Saraste M., Runswick M. J., Gay N. J., EMBO J., 1, 945-951 (1982).

13) Carafoli E., J. Biol. Chem., 267, 2115-2118 (1992).

14) Yam G., Shi L., Faustman D., J. Immunol., 162, 852-859 (1999).

15) Shindo T., Yamada M., Isomoto S., Horio Y., Kurachi Y., Br. J. Pharmacol., 124, 985-991 (1998).

16) Isomoto S., Kondo C., Yamada M., Matsumoto S., Higashiguchi O., Horio Y., Matsuzawa Y., Kurachi Y., J. Biol. Chem., 271, 2432124324 (1996).

17) Breitbart R. E., Andreadis A., Nadal-Ginard B., Ann. Rev. Biochem., 56, 467-495 (1987). 